\title{
Ethnographic Method
}

\author{
Dr. Salwa S. Alharbi \\ Prof. Of child development and education, \\ Jazan University
}

\begin{abstract}
The paper lays forth a historical background about the ethnographic research method and how it developed. Ethnography's purpose was the examination of a wide range of diverse cultural groups, the value of which not only enhances one's own experience relative to specific cultural traditions, but such comprehension also aids in the development of a much deeper appreciation for what transpires in other cultures and traditions. Supported by review of literature, the paper concludes that the point of this method is not to judge a certain culture, but to understand the subject's culture the way the natives understand it.
\end{abstract}

Culture, social group, ethnography, participants's observation, culture group, method

Ethnography is a research methodology pertaining the examination of a wide range of diverse cultural groups, the value of which not only enhances one's own experience relative to specific cultural traditions, but such comprehension also aids in the development of a much deeper appreciation for what transpires in other cultures and traditions. According to Fetterman (2010), ethnography tries to account for the difference among cultures and why such differences exist. Studying other cultures requires a deep understanding of the target society's system of beliefs, customs and practices and verbal and nonverbal language. Further, ethnography requires an understanding of the interplay of the reciprocal relationship from the individual up to society and downward from society to the individual, which shows that in many societies things are only seemingly separate when in reality there are myriad connections that tie the individual to the social unit. In a deeper sense, social relationships are the context endowing experiences a meaning. To some extent it is similar to Merton's notion of society as a web of interconnectedness among small units. By fulfilling an individual's goals, these smaller, interconnected units fulfill the overall goals and aspiration of society (Diesing, 1991). Ethnographical studies, in a perspective, quite effectively demonstrate the mutuality between the individual and society and the relationship between the macro and the micro.

According to Hammersley and Atkinson (2007), ethnography emphasizes in its method the practice of field work. It depends on observed experience to construct its theoretical model. Ethnography follows an inductive method to analyze, describe and explain cultural and social phenomena. Ethnography is also concerned with observable behaviors; it describes what people actually do, not what people ought to do. Ethnography, generally speaking, concerns itself in providing a descriptive account of any culture or society.

According to Hammersley and Atkinson (2007), the earlier Victorian ethnographers like James George Frazer and Edward Burnett Tylor practiced ethnography from a theoretical approach collecting second-hand information. These ethnographers collected data by interviewing tourists and sailors and missionaries, who visited these areas in focus and returned. This method deprives the event from its context and thus it becomes defective lacking in meaning and significance. Later ethnographers such as Boas, Malinowski, Radcliffe-Brown and Geertz stressed a new method of ethnography involving participant observations, (which required not 
only observing the sample but participating in daily life) for an extended period of time to learn about the culture in depth, from the inside out.

Data is not only collected through observations but through conducting interviews, observations, and surveys (open-ended questions). Hammersley and Atkinson (2007) explained that ethnographers gather data through interviews and observations of people's daily lives throughout an extended period of time. Ethnography also involves participant observation, where the researcher immerses oneself in the daily lives of the subjects to listen, see and understand the culture's worldview, through which this particular group of people explain and understand the particular situation in the world which is lived in. More importantly, Rossman and Rallis (2011) contend that observations should focus not only on what people actually do but also the way in which interaction occurs with one another. In terms of collecting artifacts and texts, the researcher may collect cultural symbols, art, stories, myths etc, which might help gather more in depth knowledge about religious, historical and traditional beliefs that may make this particular culture or society unique. Ellis and Bochner (1996) contend that literature, art, written history, memoirs and traditional stories are an invaluable source for ethnographic data, that not only explain the moment but endow a depth of knowledge and understanding of the past people of this same culture and how a certain behavior and attitude evolved overtime. Rossman and Rallis (2011) place extra emphasis on organizing the canvas of observation by asking important questions including 1) what is happening? 2) how is it happening? 3) what is its contextual significance or meaning? and 4) what is its relation with other events within the same culture?

Importantly, from an outsider's perspective, Yin (1989) noted, is significant in ethnographical research since it allows one to be objective and see the taken for granted little details. The collectivity method is also important since there is always a gulf between what people say about one's culture and what a group of people actually practice. Because of this there is a necessity of combining both observation and interview. Further, people may take certain details for granted to the degree that these details go unnoticed and so in an interview these details may not be discussed and during observations the researcher may notice it instead.

The point is not to judge a certain culture, as Boas (1966) stated, according to the researcher's cultural paradigm but to understand the subject's culture the way the natives understand it. After gathering all the necessary data, the researcher offers an interpretation through comparing the culture with a theoretical frame of reference. In such a way the researcher uses an inductive method of research. This unique observation method sheds light or directs focus upon a particular meaning.

Geertz (1973) distinguished two methods or ways of seeing a culture, a "thin" description or a "thick" description, in which the observer goes beyond simply describing the external surface of an event or a social practice. In regard to the "thick" description, the observer conducts an in depth analysis by seeing things related to each other and how this is significant and meaningful in that cultural context. It is a way to understand the worldview a certain society believes in and account for its moods and motivations that inform the people's actions and endow existence with meaning. Fatterman (2010) noted, from this descriptive approach, that a qualitative study allows for a well-rounded observation of an individual or group of people to understand not only what these people do but why. The answer to the why question is not from the observer's perspective but from the observed individual's perspective; why a subject thinks what one is doing is significant and what does it mean in relation to the subject's social, familial or individual worldview. Geertz (1973) wrote: "Doing ethnography is establishing rapport, selecting informants, transcribing texts, taking genealogies, mapping fields, keeping a 
diary, and so on. But it is not these things, techniques and received procedures that define the enterprise. What defines it is the kind of intellectual effort it is: an elaborate venture in, to borrow a notion from Gilbert Ryle, 'thick description'” (p. 6).

Malinowski (1961) is considered the pioneer of field work observation for an extended period of time. Malinowski used the proponent of long term participant observation approach in ethnography in his studies in New Guinea. Malinowski (1978) wrote:

Imagine yourself suddenly set down surrounded by all your gear, alone on a tropical beach close to a native village, while the launch or dinghy which has brought you sails away out of sight... Imagine further that you are a beginner, without previous experience, with nothing to guide you and no one to help you. For the white man is temporarily absent, or else unable or unwilling to waste any of his time on you. This exactly describes my first initiation into field work on the south coast of New Guinea. (p. 5)

Malinowski (1961), Radcliffe-Brown (1965), Boas (1966) and Geertz (1973) agreed that ethnography should follow a holistic approach in studying any society. Malinoswski (1961) stressed that cultures are not isolated facts, but are interconnected on the whole. These researchers stress the native voice where things must be placed into a cultural context and be understood according to the web of significations of the native of a particular culture, where its logic might be revealed, while to the outsider it might look odd. These researchers are all concerned with cultural relativity, stressing cultural relativity in the study of other cultures. The concept of relativism has been perceived as the single fundamental philosophical approach in our postmodern society. Boas (1966) started the idea of relativism in terms of anthropological studies of other cultures. Boas insisted that race, language, and culture influence a group of people. Therefore, observers of other cultures must suspend one's sense of ethnocentrism to understand cultures from one's own perspective. Hence, there are three aspects of cultural relativism that must be taken into consideration to objectively study other cultures: (1) cultures differ in fundamental beliefs about values, (2) there are no universal moral truths, each culture explains its anomalies to fit into its particular worldview, and (3) it is wrong to pass judgment on different cultural values.

From a larger perspective, every culture has developed its reality through many generations, becoming a collective of habits, ways and behaviors including meals as coping mechanisms with the environment and consequently ensuring survival. As a result one's reality becomes a worldview, the way the world is understood and through which new phenomenon is explained. It becomes one's identity and sense of decorum. Thus, Boas (1966) stressed that it is wrong to pass judgment on another's culture. In fact it is wrong to compare two cultural groups to determine which is better. Radeliffe-Brown (1965) wrote to that effect:

The usual way of looking at religion is to regard all of them or all except one, as bodies of enormous beliefs and practices. ... when we regard the religion of other peoples or at least those of what are called primitive peoples, as system of erroneous and illusory beliefs, we are confronted with the problem of how these beliefs came to be formulated and accepted.... This method of approach, even though it may seem the most direct, is not the one most likely to lead to a real understanding of the nature of religion. ( $p$. 153)

What's more, the point is that an ethnographer must not compare culture to show who is better or who is true or false. Change mostly occurs slowly - and at times unnoticeable - in the cultural context, especially in traditional cultures. Examples of a certain ritual or event taken by anthropologists remain the same over a very long period of time. What changes are the 
interpretations of these events? New interpretations arise as individuals, or rather anthropologists, see new significances of a particular event. So culture is dynamic. The understanding of a culture is constantly being weaved and is constantly in the making. No one can make a claim or has the final say about a particular culture.

Hence, for a student to understand a given culture and its contextual complexities, one account must not be relied on but rather many accounts by multiple researchers. In spite of the joy of conducting ethnographical research, it is a very challenging and time consuming process. Damon Golsorkhi, Rouleau, Seidl, and Vaara (2010) contend that the time consuming process of ethnographical research begins before starting the process of observation, the researcher must then learn the language in depth to understand the experience fully and correctly, and also to understand the decorum of a certain culture and to avoid falling into its taboo, and lastly respect that culture's beliefs and practices in order to gain trust so the people open up to the researcher. Further, a significant drawback of ethnography as a qualitative research method comes from its method of observation. That is to say, people tend to change behaviors when being observed. Therefore, in such a case the researcher may not observe what people actually do or say in daily life but rather what these people may want the observer to see by putting on one's best behavior.

\section{References}

Boas, F. (1966). Race language and culture. New York, NY: Free Press.

Damon Golsorkhi, D; Rouleau, L; Seidl, D; \& Vaara, E. (2010). Cambridge handbook of strategy as practice. New York, NY: Combridge University Press.

Diesing, P. (1991). How does social science work? Reflections on practice. Pittsburgh, PA: University of Pittsburgh.

Ellis, C., \& Bochner, A. P. (1996). Composing ethnography: Alternative forms of qualitative writing. Walnut Creek, Calif.: AltaMira Press.

Fetterman, D. (2010). Ethnography: Step-by-step (3rd ed.). California: Sage Publications, Inc.

Geertz, C. (1973). Thick description: Toward an interpretative theory of culture. The interpretation of cultures. New York: Basic Books.

Hammersley, M., \& Atkinson, P. (2007). Ethnography: Principles in practice (3rd ed.). New York, NY: Taylor \& Francis e-Library.

Malinowski, B. (1961). Argonauts of the western Pacific; an account of native enterprise adventure in the Archipelagoes of Melanesian New Guinea. New York, NY: Dutton.

Radeliffe-Brown, A. (1965). Structure and function in primitive society. New York: The Free Press.

Rossman, G. B., \& Rallis, S. F. (2011). Learning in the field: An introduction to qualitative research (3rd ed.). Thousand Oaks, Calif.: Sage Publications.

Yin, R. K. (1989). Case study research: Design and methods. Newberry Park, Calif.: Sage Publications. 